ELKOM, Vol.11, No.2, Desember 2018, pp. 56 - 62

p-ISSN : 1907-0012 (print)

e-ISSN : 2714-5417 (online)

http://journal.stekom.ac.id/index.php/elkom

page 56

\title{
SISTEM PENGENDALIAN LAMPU BERBASIS ARDUINO MENGGUNAKAN BLUETOOTH PADA SMARTPHONE ANDROID DI RUMAH QUR'AN AL-FATAH
}

\author{
Husamuddin Islami ${ }^{1}$, Laksamana Rajendra Haidar Azani Fajri², Moh Muthohir ${ }^{3}$ \\ ${ }^{1}$ Progdi Sistem Komputer- STEKOM, husamuddin@ gmail.com \\ ${ }^{2}$ Progdi Sistem Informasi, STMIK Provisi, haidar@provisi.ac.id \\ ${ }^{3}$ Progdi Teknik Komputer- STEKOM, muthohir@stekom.ac.id \\ Jl. Majapahit 605, Semarang, telp/fax : 024-6717201-02
}

\section{ARTICLE INFO}

Article history:

Received 19 November 2018

Received in revised form 23 Nov 2018

Accepted 25 Nov 2018

Available online 13 Desember 2018

\begin{abstract}
The purpose of this research is to produce tangible results in providing comfort or convenience in turning on or off the night life at home everyday, especially for people who forget to turn off the lights. The method used in making microcontroller-based home lighting control using an android smartphone is. This research method consists of several stages, analysis methods, design methods, implementation testing methods, and maintenance. The results achieved are improving the aspects of comfort and convenience for agencies, where this series of tools works after bluetooth devices are available on android smartphones. connected to a bluetooth module which is connected to the Arduino microcontroller. Basically, the principle of using this tool is that users must be able to operate a smartphone based on the Android operating system. The conclusion of this research is that the Arduino-based light control device using bluetooth can fulfill its function to control the lights properly and the device is designed to be minimalist and safety so it is safe to use.
\end{abstract}

Keywords: Control of lights, Arduino UNO, Smartphone Android, bluetooth

\section{Pendahuluan}

Teknologi informasi dan komunikasi pada era sekarang ini menunjukan perkembangan yang sangat pesat. Hal ini disebabkan oleh tren media komunikasi yang sedang mewabah dalam masyarakat sekarang ini. Salah satu contoh yang bisa kita lihat adalah masyarakat cenderung menggunakan telepon genggam untuk menjadi media komunikasi antara satu orang kepada orang lain yang berada di tempat lain. Kenyataan telah menjadi sebuah fenomena yang sudah lazim di tengah masyarakat dunia yaitu telepon genggam bermetamorfosis menjadi "smartphone" berbasis android. Salah satu keunggulan dari smartphone android yang paling banyak dimanfaatkan oleh pengguna ponsel cerdas ini adalah mudahnya melakukan pemrograman dan dapat disambungkan dengan mikrokontroler seperti arduino dan memanfaatkan fasilitas bluetooth yang ada pada smartphone android, sehingga dapat digunakan untuk melakukan penelitian.

Dalam suatu ruangan yang dipenuhi peralatan elektronik, alat kendali sangatlah penting mengingat dampak pemakaian peralatan listrik yang tidak terkontrol akan menyebabkan umur peralatan listrik tidak panjang dan dapat terjadi pembengkakan biaya tagihan listrik.

Received Nov 19, 2018; Revised Nov 23, 2018; Accepted Nov 25, 2018 
Untuk mengatasi masalah tersebut, perlu dikembangkan sebuah sistem yang berfungsi untuk mengontrol seluruh peralatan elektronik dalam satu alat kendali yang memanfaatkan Bluetooth sebagai media komunikasi yang tertanam pada smartphone. Maka dihasilkan ide untuk mengembangkan alat bantu kendali peralatan elektronik berbasis Bluetooth pada smartphone Android.

Penelitian ini, secara umum bertujuan untuk mengembangkan sistem kendali lampu di asrama rumah Qur'an Al-Fatah dengan kendali button on/off di smartphone android dengan memanfaatkan fasilitas bluetooth.

\section{Kajian Penelitian yang Relevan}

Berikut kajian-kajian relevan yang penulis catut dari hasil penelitian terdahulu yang berhubungan dengan penelitian yang sedang penulis kaji guna mendukung penyusunan penelitian ini:

Model Kontrol Lampu Ruangan Menggunakan Sensor Pir Dan Sensor Cahaya [1], Rancang Bangun Sistem Pengontrol Intensitas Cahaya pada Ruang Baca Berbasis Mikrokontroler ATMEGA16 [2], Sistem Kontrol Penerangan Menggunakan Arduino UNO pada Universitas Ichsan Gorontalo. [3]

\section{Kajian Teoritis}

\section{a. Lampu}

Lampu merupakan bagian dari bangunan pelengkap yang dapat diletakkan atau dipasang di dalam ruangan ataupun di luar ruangan. Didalam ruangan yang digunakan untuk menerangi ruang tamu, kamar tidur, ruang keluarga, dapur, dan lainya sedangkan untuk diluar ruangan yang digunakan untuk menerangi teras, jalan, taman dan lainnya. Sedangkan lampu adalah sebuah peranti yang memproduksi cahaya. Kata "lampu" dapat juga berarti bola lampu. Ada berbagai macam lampu diantaranya lampu pjiar, lampu neon, lampu busur, lampu mercuri, LED, dan sebagainya. [4]

\section{b. Arduino}

Arduino merupakan mikrokontroller atau sebuah platform komputasi fisik berbasis rangkaian input/output sederhana dengan mengimplementasikan bahasa processing yang bersifat open source. Dengan menggunakan arduino, perangkat lunak interaktif dapat dikembangkan dengan sangat baik. [5].

Kelebihan dari arduino ini adalah (1) harga perangkat kerasnya relatif murah, (2) pemrogramannya sederhana dan mudah, (3) Perangkat lunak Arduino IDE bersifat open source.

\section{c. Relay}

Relay memiliki fungsi seperti remote. Relay dapat dikatakan sebagai rangkaian elektronika pengendali jarak jauh. Cara kerjanya mirip dengan kontaktor, yang akan bekerja jika ada arus listrik pada koil. Sehingga terdapat istilah normally open yang artinya arus listrik tidak mengalir karena tidak terhubung, dan Normally close yang berarti arus listrik mengalir karena terhubung [6].

\section{Kerangka Berfikir}

Berikut kerangka berfikir dalam penelitian ini:

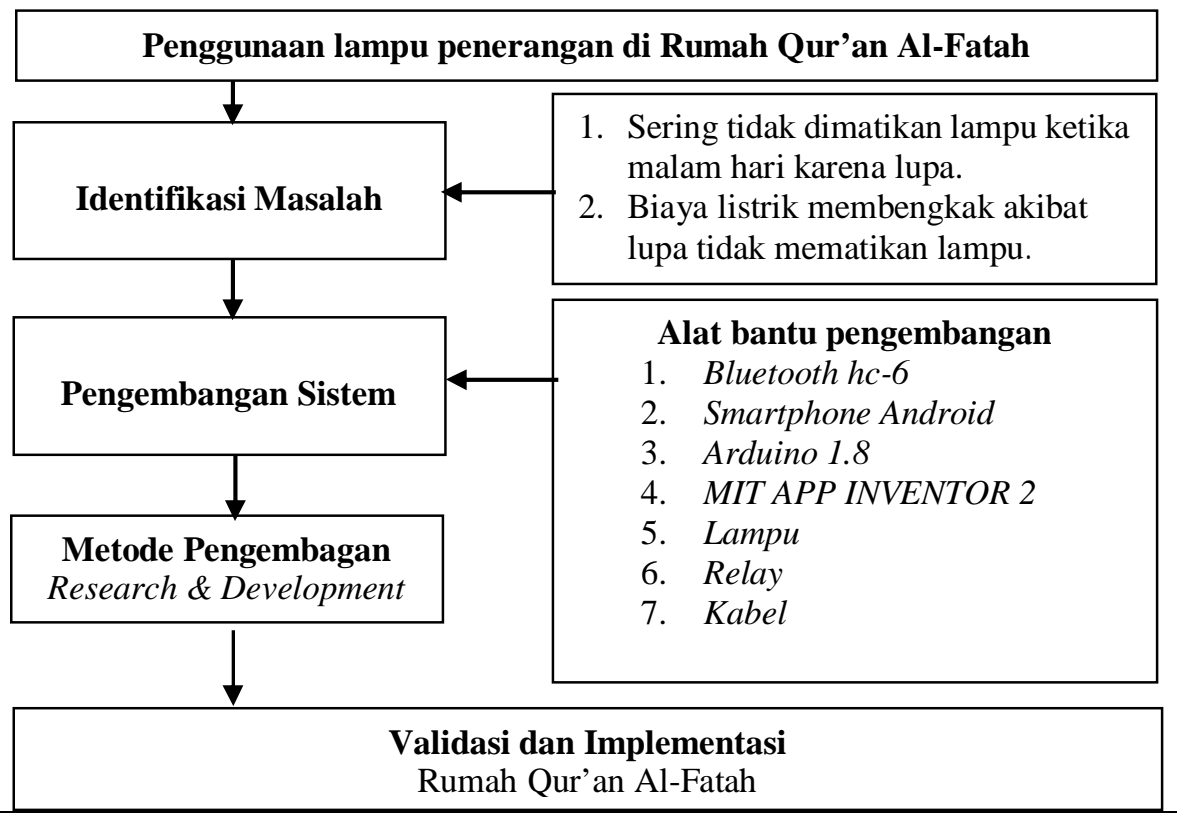

Perancangan Pengendalian Lampu Berbasis Arduino Menggunakan Bluetooth Pada Smartphone Android di Rumah Qur'an Al-Fatah 


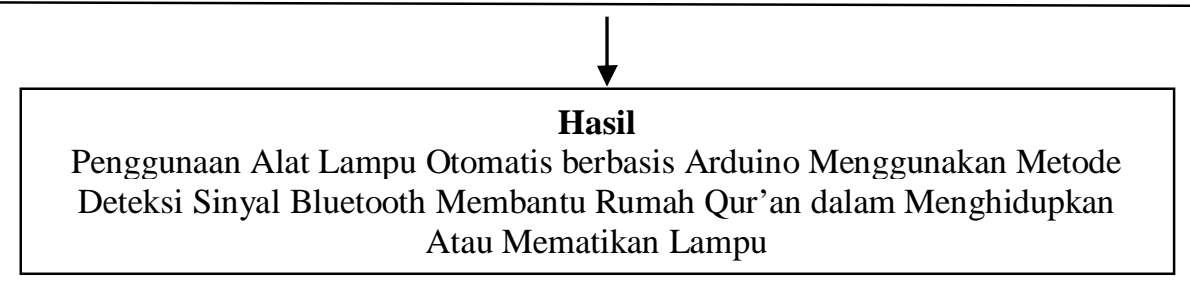

Gambar 1. Kerangka Berfikir

\section{Metode Penelitian}

Metode penelitian yang digunakan untuk pengembangan aplikasi ini yaitu metode pengembangan Research and Development (R\&D). Metode ini digunakan untuk menghasilkan produk tertentu dan menguji keefektifan produk yang dimaksud. Adapun tahapan dalam metode ini terdiri dari 10 langkah seperti tercantum pada gambar 2 .

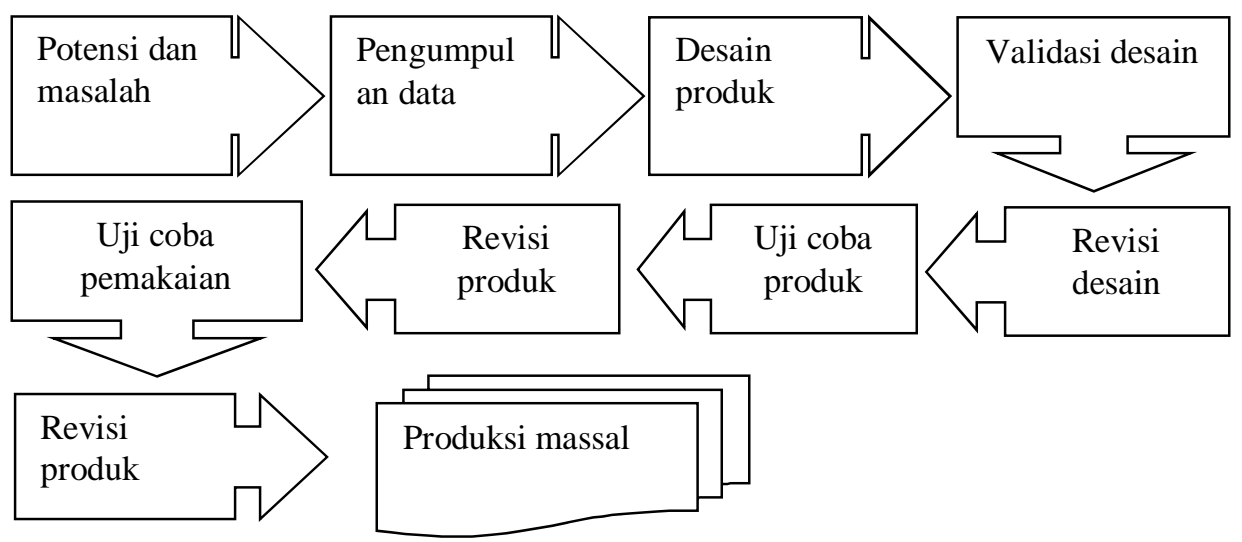

Gambar 2. Metode R \& D [7]

Dalam penelitian ini hanya menerapkan 6 langkah saja, yaitu:

\section{Potensi dan Masalah}

Sistem yang lama menggunakan kendali manual yaitu dengan cara kontak fisik langsung antara user dan saklar lampu sebagai penyambung atau pemutus arus listrik untuk menghidupkan atau mematikan lampu. Cara manual seperti ini kurang efektif untuk di kalangan para santri karena kebiasaan mereka yang suka lupa untuk mematikan lampu. Oleh karena itu, peneliti merancang sebuah sistem yang berfungsi sebabai alat kendali lampu penerangan rumah berbasis smartphone android sebagai media kontrol on/off lampu.

\section{Pengumpulan Data}

Setelah potensi dan masalah dapat ditunjukan secara faktual, maka lanhkag berikutnya perlu dikumpulkan berbagai informasi dan studi literatur yang dapat digunakan sebagai bahan untuk pengembangan aplikasi yang diharapkan menjadi solusi atas masalah yang ditemukan.

\section{Desain Produk}

Desain sistem ini masih bisa berubah karena ke-efektivitannya belum dapat dibuktikan sehingga disebut hipotetif, dan hasilnya akan dapat diketahui setelah melalui pengujian.

Validasi Desain

Validasi desain merupakan proses penilaian dari validator apakah rancangan produk lebih efektif atau tidak.

\section{Revisi Desain}

Setelah desain produk divalidasi melalui diskusi dengan validator, maka akan dapat diketahui kelemahannya. Kelemahan tersebut selanjutnya dicoba untuk dikurangi dengan cara memperbaiki desain yang bertugas memperbaiki desain adalah peneliti yang mau menghasilkan produk tersebut.

\section{Ujicoba Produk}

Pengujian dapat dilakukan dengan ekperimen yaitu membandingkan efektivitas dan efesiensi sistem kerja lama dengan yang baru

\section{ELKOM Vol. 11, No. 2, Desember 2018: 56 - 62}




\section{Hasil dan Pembahasan}

\section{Desain Interface}

Desain interface aplikasi pengendali lampu yang ada di Smartphone yang dibuat dan dijabarkan agar jelas seperti gambar 3 .

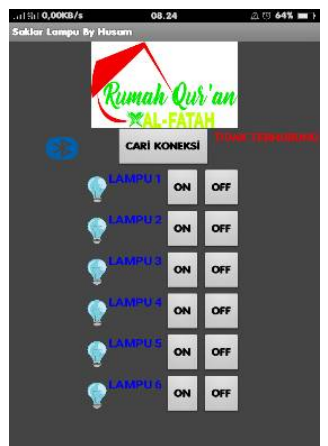

Gambar 3. Aplikasi pengendali lampu

Selanjutnya, untuk desain rangkaian simulator lampu seperti gambar 4.

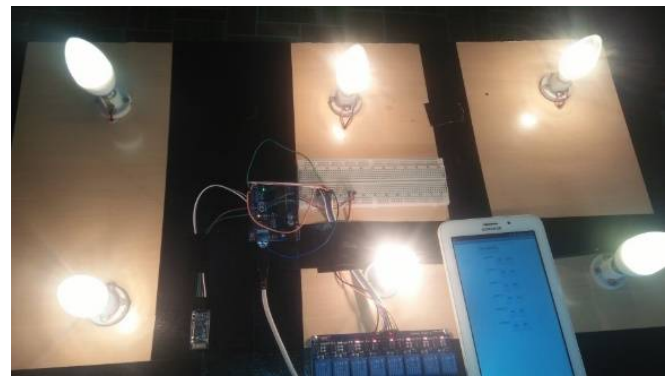

Gambar 4. Simulator lampu

\section{Hasil Pengujian Sistem}

Pengujian software dalam penelitian ini dilaksanakan oleh pihak user atau pengguna, sedangkan untuk metode pengujian yang digunakan adalah pengujian At communication device. Pengujian At communication device adalah pengujian system yang menggunakan konektivitas. Metode ini digunakan untuk mengetahui apakah perangkat lunak berfungsi dengan benar. Pengujian At communication device merupakan metode perancangan data uji yang didasarkan pada sepesifikasi perangkat lunak yang dibuat.

Adapun Aspek pengujian perancangan pengendalian lampu berbasis arduino uno menggunakan bluetooth pada smartphone android di rumah qur'an al-fatah, seperti pada tabel 1.

Tabel 1. Aspek pengujian

\begin{tabular}{|l|l|l|}
\hline \multicolumn{1}{|c|}{ Kelas Uji } & \multicolumn{1}{|c|}{ Butir Uji } & \multicolumn{1}{c|}{ Jenis Pengujian } \\
\hline Connect & Connect & $\begin{array}{l}\text { At communication } \\
\text { device }\end{array}$ \\
\hline $\begin{array}{l}\text { Jangkauan } \\
\text { Bluetooth }\end{array}$ & $\begin{array}{l}\text { Kendali lampu tanpa } \\
\text { penghalang dan ada } \\
\text { penghalang dengan } \\
\text { jarak 1-13 meter }\end{array}$ & $\begin{array}{l}\text { At communication } \\
\text { device }\end{array}$ \\
\hline
\end{tabular}

Hasil uji konektivitas bluetooth seperti pada tabel 2. 
Tabel 2. Hasil pengujian koneksi bluetooth

\begin{tabular}{|c|l|l|l|l|}
\hline No & $\begin{array}{l}\text { Status } \\
\text { Bluetooth }\end{array}$ & $\begin{array}{l}\text { Yang } \\
\text { diharapkan }\end{array}$ & Pengamatan & Kesimpulan \\
\hline $\mathbf{1}$ & Aktif & $\begin{array}{l}\text { Dapat } \\
\text { menampilkan } \\
\text { nama } \\
\text { Bluetooth }\end{array}$ & $\begin{array}{l}\text { Tampilan Nama } \\
\text { Bluetooth }\end{array}$ & $\begin{array}{l}\text { [-] Diterima } \\
\text { [ ] Ditolak }\end{array}$ \\
\hline $\mathbf{2}$ & Tidak Aktif & $\begin{array}{l}\text { Tidak dapat } \\
\text { terhubung }\end{array}$ & $\begin{array}{l}\text { Tidak ada } \\
\text { Koneksi } \\
\text { Bluetooth }\end{array}$ & $\begin{array}{l}\text { [ ] Diterima } \\
\text { [-] Ditolak }\end{array}$ \\
\hline $\mathbf{3}$ & Terhubung & $\begin{array}{l}\text { Dapat } \\
\text { menampilkan } \\
\text { tulisan } \\
\text { "Terhubung } \\
\text { berwana } \\
\text { Hijau" }\end{array}$ & $\begin{array}{l}\text { Pemberitahuan } \\
\text { "Connected" }\end{array}$ & $\begin{array}{l}\text { [-] Diterima } \\
\text { [ ] Ditolak }\end{array}$ \\
\hline
\end{tabular}

Hasil uji jangkauan bluetooth seperti pada tabel 3.

Tabel 3. Hasil pengujian jangkauan bluetooth

\begin{tabular}{|c|c|c|c|}
\hline No & Jangkauan & Kondisi Ruangan & Kesimpulan \\
\hline \multirow{2}{*}{1} & \multirow{2}{*}{$1-10$ meter } & Tanpa Penghalang & $\begin{array}{l}\text { [-] Diterima } \\
\text { [ ] Ditolak }\end{array}$ \\
\hline & & Ada Penghalang & $\begin{array}{l}\text { [-] Diterima } \\
\text { [ ] Ditolak }\end{array}$ \\
\hline \multirow{2}{*}{2} & \multirow{2}{*}{$11-12$ meter } & Tanpa Penghalang & $\begin{array}{l}\text { [-] Diterima } \\
\text { [ ] Ditolak }\end{array}$ \\
\hline & & Ada Penghalang & $\begin{array}{l}\text { [ ] Diterima } \\
\text { [-] Ditolak }\end{array}$ \\
\hline \multirow{2}{*}{3} & \multirow{2}{*}{13 meter } & Tanpa Penghalang & $\begin{array}{l}\text { [-] Diterima } \\
\text { [] Ditolak }\end{array}$ \\
\hline & & Ada Penghalang & $\begin{array}{l}\text { [ ] Diterima } \\
\text { [-] Ditolak }\end{array}$ \\
\hline
\end{tabular}

\section{Pengujian Konektivitas Sensor Terhadap Aplikasi}

Pengujian dari seluruh alat yang telah dilakukan, pada mulanya dilakukan pengecekan sambungan data serial. Apabila sudah terhubung, ketika Tombol menu On pada aplikasi Android ditekan, maka program akan mengirimkan perintah yang berupa data string ke Mikrokontroller Arduino Severino melalui Bluetooth kemudian diteruskan ke Pin Digital yang ada pada Arduino Severino Board (ditetapkan sebagai Output) sehingga lampi dapat menyala. Begitu pula sebaliknya, apabila tombol $O F F$ pada aplikasi yang ditekan maka lampu akan padam.

Hasil dari pengujian sistem kendali lampu penerangan dengan menggunakan lampu. dapat dilihat pada Tabel 4. Diasumsikan bahwa, sebelum data dikirim kondisi sistem dalam keadaan Low atau tidak ada masukan (belum ada lampu yang menyala). dari Tabel tersebut dapat dilihat bahwa, ketika salah satu tombol ON pada tampilan aplikasi ditekan, maka Output (lampu) akan menyala dan ketika tombol OFF yang ditekan, maka Output (lampu) akan padam.

Tabel 4. Hasil pengujian sistem kendali lampu

\begin{tabular}{|c|c|c|c|c|c|}
\hline No & Lampu & $\begin{array}{c}\text { Tombol yang } \\
\text { di tekan }\end{array}$ & $\begin{array}{c}\text { Yang di } \\
\text { harapkan }\end{array}$ & Pengamatan & Kesimpulan \\
\hline 1 & Lampu 1 & ON & Hidup & Hidup & $\begin{array}{l}\text { [-] Diterima } \\
\text { [ ] Ditolak }\end{array}$ \\
\hline
\end{tabular}

ELKOM Vol. 11, No. 2, Desember 2018: $56-62$ 


\begin{tabular}{|c|c|c|c|c|c|}
\hline & & OFF & Mati & Mati & $\begin{array}{l}\text { [-] Diterima } \\
\text { [ ] Ditolak }\end{array}$ \\
\hline \multirow{2}{*}{2} & \multirow{2}{*}{ Lampu 2} & $\mathrm{ON}$ & Hidup & Hidup & $\begin{array}{l}\text { [-] Diterima } \\
\text { [ ] Ditolak }\end{array}$ \\
\hline & & OFF & Mati & Mati & $\begin{array}{l}\text { [-] Diterima } \\
\text { [ ] Ditolak }\end{array}$ \\
\hline \multirow{2}{*}{3} & \multirow{2}{*}{ Lampu 3} & $\mathrm{ON}$ & Hidup & Hidup & $\begin{array}{l}\text { [-] Diterima } \\
\text { [ ] Ditolak }\end{array}$ \\
\hline & & OFF & Mati & Mati & $\begin{array}{l}\text { [-] Diterima } \\
\text { [ ] Ditolak }\end{array}$ \\
\hline \multirow{2}{*}{4} & \multirow{2}{*}{ Lampu 4} & $\mathrm{ON}$ & Hidup & Hidup & $\begin{array}{l}\text { [-] Diterima } \\
\text { [ ] Ditolak }\end{array}$ \\
\hline & & OFF & Mati & Mati & $\begin{array}{l}\text { [-] Diterima } \\
\text { [ ] Ditolak }\end{array}$ \\
\hline \multirow{2}{*}{5} & \multirow{2}{*}{ Lampu 5} & $\mathrm{ON}$ & Hidup & Hidup & $\begin{array}{l}\text { [-] Diterima } \\
\text { [ ] Ditolak }\end{array}$ \\
\hline & & OFF & Mati & Mati & $\begin{array}{l}\text { [-] Diterima } \\
\text { [ ] Ditolak }\end{array}$ \\
\hline \multirow{2}{*}{6} & \multirow{2}{*}{ Lampu 6} & $\mathrm{ON}$ & Hidup & Hidup & $\begin{array}{l}\text { [-] Diterima } \\
\text { [ ] Ditolak }\end{array}$ \\
\hline & & OFF & Mati & Mati & $\begin{array}{l}\text { [-] Diterima } \\
\text { [ ] Ditolak }\end{array}$ \\
\hline
\end{tabular}

\section{Simpulan dan Saran}

\section{Simpulan}

Berdasarkan hasil penelitian yang dilakukan dalam pengembangan pengendalian lampu berbasis Arduino Uno menggunakan bluetooth pada smartphone Android di rumah Qur'an Al-Fatah ini menghasilkan kesimpulan: (1) alat kendali lampu berbasis arduino menggunanakan bluetooth telah dapat memenuhi fungsinya untuk mengendalikan lampu dengan baik dan perangkat dirancang minimalis dan safety sehingga aman untuk digunakan, (2) Komunikasi hanya dapat menjangkau jarak maksimum 13 meter karena menggunakan komunikasi bluetooth dan tingkat keakuratan pengiriman sangat tinggi pada jarak jangkau dibawah 9 meter dan gangguan seperti gagalnya pengiriman perintah terjadi pada jarak 10- 13 meter, (3) Hanya bisa dikendalikan pada satu pengendali saja dalam waktu yang bersamaan.

\section{Saran}

Berdasarkan penelitian yang telah dilakukan, maka peneliti menyarankan:

1) Dari segi komunikasi, perangkat hanya dapat mengirimkan perintah menggunakan bluetooth sehingga jarak jangkau maksimum 13 meter, untuk pengembangan lebih lanjut dapat menggunakan komunikasi wifi/sms sehingga dapat digunakan secara jarak jauh.

2) Diharapkan kedepannya interface aplikasi dapat dirancang lebih baik lagi dan lebih user friendly.

\section{Daftar Pustaka}

[1] Syafaat., Achmad. (2016). Model Kontrol Lampu Ruangan Menggunakan Sensor Pir Dan Sensor Cahaya, Jurnal FMIPA Universitas Pakuan, 4 (2), 25-33.

[2] Kelana., M., Muid., A., \& Nurhasanah. (2015). Rancang Bangun Sistem Pengontrol Intensitas Cahaya pada Ruang Baca Berbasis Mikrokontroler ATMEGA16. Jurnal POSITRON, V(1), 05-10.

[3] Bahrin. (2017). Sistem Kontrol Penerangan Menggunakan Arduino UNO pada Universitas Ichsan Gorontalo. Jurnal ILKOM , 9 (3), 282-289

[4] Diding Suhardi. (2015). Prototipe Controller Lampu Penerangan LED (Light Emitting Diode) Independent Bertenaga Surya. Jurnal Gamma, 10(1). Universitas Muhammadiyah Malang

[5] Sokop, J.S., Mamahit., J.D \& Sompie., S. (2016). Trainer Periferal Antarmuka Berbasi Mikrokontroler Arduino Uno. Jurnal Teknik Elektro \& Komputer UNSRAT, 5(3), 13-23. 
[6] Turang, Daniel A.O., (2015). Pengembangan Sistem Relay Pengendalian dan Penghematan Pemakaian Lampu Berbasis Mobile. SEMNASIF, 1(1), 75-85.

[7] Sugiyono. (2014). Metode Penelitian Pendidikan (Pendekatan Kuantitatif, Kualitatif \& RnD), Bandung : Alfabeta

ELKOM Vol. 11, No. 2, Desember 2018: 56 - 62 